\title{
Izgrajevanje lokalne in regionalne identitete
}

\section{Zakaj skrb?}

V zgodovini je bilo mnogo poskusov ustvarjanja prostorov, ki bi lahko zadovoljevali raznovrstne družbene potrebe, obenem pa estetsko zadoščali potrebam vsakdanjih uporabnikov in obiskovalcev. Te prostore so gradili v celoti, na osnovi sprejete posamezne odločitve, ali $Z$ inkrementalnimi oziroma postopnimi koraki preobrazbe - kar je značilno za večino nenačrtovanih naselbin -, pri čemer so nove mestne površine dodajali obstoječim naselbinskim jedrom, pogosto pa so nove prostore ustvarjali $z$ združevanjem obeh postopkov.

Mesta so dobila prepoznaven značaj zaradi številnih dejavnikov: naravnih topografskih in pokrajinskih razmer; razpoložljivosti gradiv, poznavanja gradbene tehnologije, značilnosti gospodarstva in proizvodnje, družbenopolitičnih dejavnikov, predvsem pa tedanjih oblikovalskih pristopov. Takšno prepoznavnost naselij, ki se kaže v fizičnih oblikah, vzorcih in prostorski organizaciji, skupaj $z$ elementi naravnega okolja, imenujemo lokalna identiteta. $\mathrm{V}$ teoriji urbanističnega oblikovanja se ta kakovost imenuje tudi genius loci, "cluh prostora".

Genius loci je antična predstava, ki izvira iz verovanja, da "... vsaka posamezna entiteta (stvaritev, stvar) ima svoj genius-a 'duha varuha'; ta duh daje življenje ljudem in prostorom, jih spremlja od rojstva do smrti in jim določa značaj” (Norberg-Schutz, 1980, str. 18). Zaradi neskončnega števila načinov medsebojnih povezav med posameznimi elementi smo priclobili veliko bogastvo prepoznavnih prostorov $\mathrm{z}$ izrazitimi lokalnimi identitetami, prizorišča številnih vsakoletnih "romanj". Praga, Benetke,
Perugia, Oxford in Sienna so le nekateri prostori enkratnih in prepoznavnih kakovosti.

Poleg tega da imajo nekatera mesta enkraten in prepoznaven značaj, lahko tudi skupine mest prikazujejo določeno skupno prepoznavnost, tako, ki je lastna posameznemu območju ali regiji. V takih primerih teorija urbanističnega oblikovanja govori o regionalni identiteti. Mesta $\mathrm{v}$ grofiji Somerset ali vasi v hribovju Cotswold v Angliji, slemenske vasi v italijanski Umbriji ali ameriške prerijske hiše so primeri močnih regionalnih identitet.

Od leta 1945 se je zgodilo veliko sprememb v načinih izgradnje naselij in posameznih stavb. Namesto precej lokalističnih gradbenih tradicij so se razvile nove oblike proizvodnje grajenega okolja. Tradicionalno grajene stavbe in lokalna urbana območja nadomešča sodobno grajena krajina, ki se zelo hitro širi (Relph, 1987). Za današnja mesta je značilna prevlada večnadstropnih poslovnih stavb, obsežnih stanovanjskih naselij, trgovskih območij in drugih oblik združevanja lokalov drobne prodaje.

Mestni prebivalci se umikajo $\mathrm{v}$ slikovita podeželska naselja, da bi se izognili bivanju v spremenjenih mestih. Ta beg $\mathrm{v}$ predmestja in na podeželje so spremljale številne špekulativne operacije stanovanjske gradbnje. Tovistno ponudbo graditelji prikazujejo, kot zanimivo in dosegljivo za družine srednjega dohodkovnega razreda. Za namene trženja v različnih regijah so izumili številne "neoljudske" arhitekturne podobe. $\mathrm{V}$ procesu ustvarjanja "novih vasi" so bila mnoga zgodovinska območja nepovratno spremenjena, kajti v tovrstnih novih
Essex Lokalna identiteta Regionalna identiteta Velika Britanija

Na veliko žalost številnih ljudi so posamezni kraji med seboj čedalje bolj. podobni. Problem je še zlasti opazen $v$ novih stanovanjskih območjih, $k i$ nimajo prepoznavnega značaja, in se jih pogosto opisuje kot anonimna okolja "kjerkoli". Enako so označena mnoga nakupovalna območja in mestna središča, kjer se nadčasovne kakovosti tradicionalne mestne podobe postopno krhajo.

Na splošno se od leta 1970 povečuje zanimanje za načine preusmerjanja tega procesa. Arhitekti, planerji in urbanisti raziskujejo metode $v$ načrtovalskih postopkih, $s$ pomočjo katerih bi oblikovali nove lokalne in regionalne identitete.

$V$ različnih teoretskih pristopih so bile predstavljene metodološke predpostavke, ki jih zasledimo $v$ mnogih urbanističnih zasnovah in arhitektonskih rešitvah na večini celin in $v$ različnih kulturnih sredinah.

Essex Great Britain Local identity Regional identity

To many people's deep regret, almost everywhere seems to be getting more and more like everywhere else. This problem is especially evident in new housing areas, frequently described as anonymous "anywhere" environments, lacking in any distinguishable character. The same criticism is applied to many shopping precincts and town centres where the long existing qualities of traditional townscapes are gradually being eroded.

Since about 1970, there has been an increasing and widespread interest in ways of reversing this process. Architects, planners and urban designers have been searching for methods and design approaches in order to construct new local and regional identity.

Different theoretical schools have put forward their own methodological propositions, evidence of which can be found in many urban design and architectural schemes across many continents and cultural regions. 


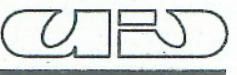

št. 32, 33/1997

projektih je čutiti pomanjkanje tako lokalnih gradbenih tradicij kakor tudi podedovanih kakovosti posameznih območij.

Na veliko žalost številnih ljudi so si posamezni kraji med seboj čedalje bolj podobni. Nekateri kritiki pripisujejo radikalna spreminjanja "korporizaciji" mest '(Relph, 1987), nekateri povojnemu planiranju in oblikovalskim filozofijam (Jacobs, 1961, Ravetz, 1986, Valižanski princ, 1989), nekateri pa finančnim institucijam, ki dajejo prednost posameznim grajenim oblikam, ki jih je lažje prodajati.

Nekateri teoretiki povezujejo odtujenost, ki jo ljudje čutijo $\mathrm{v}$ teh anonimnih okoljih, s sprememba$\mathrm{mi}$ in govorijo o "krizi urbane identitete" (Nicolin, 1989). Drugi nadaljujejo s trditvijo, da sta "prostor in osebna identiteta posameznika pogojena, da je prostor skupni imenovalec razumevanja in pripadnosti posameznika in da so posamezni deli prostora elementi asociacije človeka $z$ lastno identiteto; identiteta posameznika je $\mathrm{v}$ ozki povezavi $z$ identiteto prostora, iz katerega izhaja (NorbergSchultz, 1980). Bolj postajamo del večjega univerzalnega sistema, večja je potreba po predstavljanju lastnega individualizma ter osebnih ali skupinskih stremljenj. Na najnižji, osebni ravni so na-

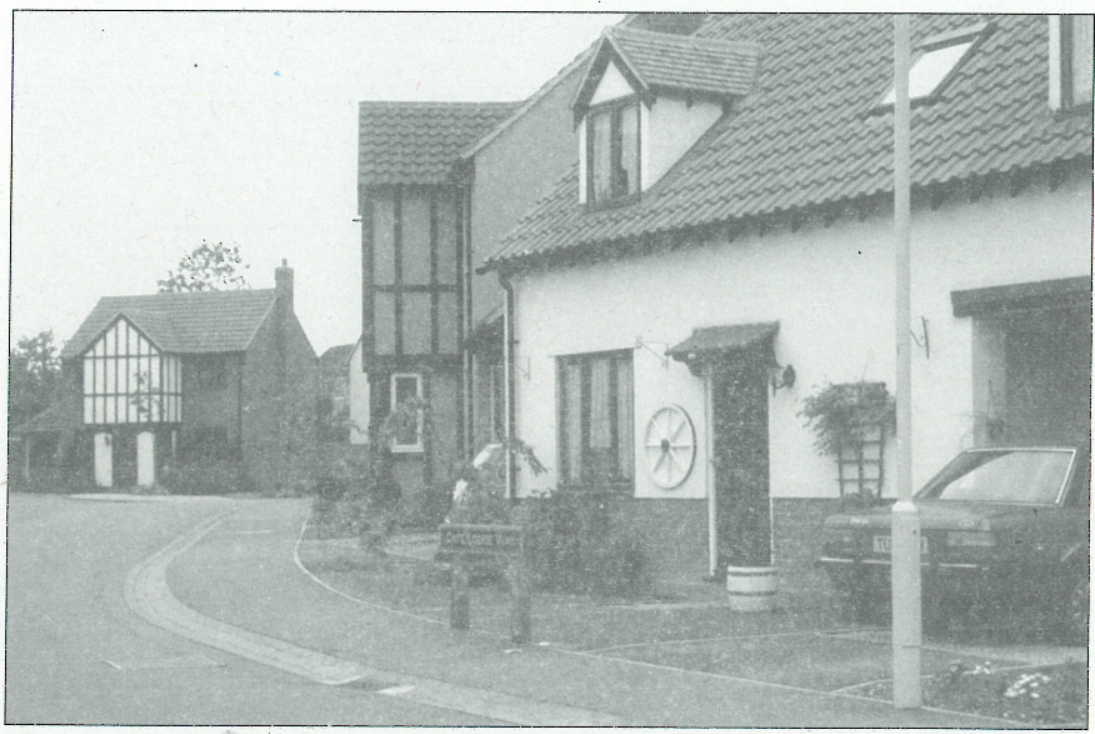

Slika 1: Vas Finchingfield v grofiji Essex vadno ta stremljenja izražena s personalizacijo lastnine.

Toda odziv na univerzalno anonimnost se ne izraža le na osebni ali posamezni ravni. Podobni občutki so izraženi tudi $\mathrm{v}$ večjih prostorskih dimenzijah. Mesta in cele regije $\mathrm{v}$ neprestani tekmi za vedno bolj gibljivim kapitalom in naložbami, vedno bolj spoštujejo vrednost prepoznavnega regionalnega značaja za privabljanje vodilnih poslov (in poslovnežev) in $z$ njimi novih podjetij ter delovnih mest. V Veliki Britaniji in drugih državah redno "proizvajajo" nove urbanistične zasnove in navodila (o rabi prostora). $\mathrm{V}$ njih je jasno izražena skrb posameznih lokalnih oblasti in lokalnega prebivalstva o podpori novemu razvoju, ki bi izražal lokalni ali regionalni značaj kulturne in grajene krajine lastnega prostora.

Podobna iskanja lokalne in regionalne identitete so enako močno zastopana v "dekoloniziranih" drŽavah Afrike in Azije. Tam so učinki modernizacije razvidni v dramatičnem begu od tradicionalnih kulturnih izročil. Odločanje o vprašanju, "kaj je lahko in kaj ne more biti v prostoru, prevzema politične in čustvene dimenzije $\mathrm{v}$ boju za kulturno preživetje” (Abel, 1986).

Nekako od leta 1970 opažamo povečano in obsežno zanimanje za spremembo tega procesa in iskanje vloge planiranja, arhitekture in urbanizma pri uresničevanju le-tega. Mnogim planerjem, arhitektom in urbanistom se tak pristop še vedno prikazuje kot novost, neznanka, čeprav v resnici ni tako nov in so o njem razpravljali že dolgo tako s teoretičnega kot praktičnega vidika.

Gre za odnos med teorijo in prakso, iz katerega bi morali potegniti dobiček, kajti praksa brez teorije vodi $v$ nesmiselno prevzemanje zunaj konteksta, teorija brez prakse pa je le akademsko igračkanje. Potreba po spravi med teorijo in prakso je nujna, če želimo preprečiti proizvodnjo "sprejemljive" povprečnosti ali pastiche arhitekture in urbanizma. 


\section{Lokalna in regionalna identiteta $\mathrm{v}$ teoriji in praksi}

V sodobni urbanistični teoriji je predmet lokalne identitete doseganje lokalnega (in regionalnega) značaja s pomočjo novega oblikovanja, ki poudarja enkratnost prostora (prostorov) in se izraža s konkretnim fizičnim oblikovanjem stavb ter $z$ njihovo razmestitvijo. Cilj je proizvodnja take urbanistične podobe, ki je lokalno specifična in hkrati del svetovne dediščine. Urbanisti in arhitekti, ki spoštujejo ta koncept, pri svojem delu uporabljajo raznovrstne metode urbanističnega oblikovanja in arhitekturnega izrazja. Vendar, upoštevanje lokalne in regionalne identitete pri oblikovanju lokalnih urbanih prostorov ne sovpada $s$ posameznim slogom ali oblikovalsko filozofijo.

Iz zgodovine so znani mnogi primeri opredeljevanja pojma (lokalne ali regionalne) identitete in poskusi oblikovanja praktičnih metod doseganja posebnosti. Namen tega besedila ni podrobno popisati teoretične in praktične namere, pač pa osnovna vodila in metode, $\mathrm{ki}$ bi jih lahko uporabljali tudi danes.

Zaradi velikega števila oblikovalskih problemov na trgu Campo del Santo $v$ Sienni (Toscana) so vložili leta 1292 veliko naporov v koordinacijo posameznih (raznovrstnih) elementov grajenega okolja v "zclruženo" in prepoznavno celoto. V obdobju renesanse je bilo v Italiji več podobnih dejanj, prav tako $\mathrm{v}$ drugih regijah, kjer so želeli oblikovati mesta, ki bi bila moderna in bi hkrati imela lokalni ali regionalni značaj. Zato so mestni veljaki najemali arhitekte, slikarje in kiparje, ki so pomagali pri ustvarjanju enkratnih in prepoznavnih prostorov.

Dubrovnik je dober primer takega početja. Tam so trgovci za pojavljanje na lokalnem trgu morali priskrbeti določeno količino kamna s tega območja. Posamez- ni lokalni graditelji in obrtniki so prav tako morali upoštevati lokalno gradbeno zakonodajo, da bi zgradili mesto, v katerem bi bili posamezni elementi, na ravni celotne zasnove (mreže), stavbne tipologije in oblikovanja detajlov, poenoteni. Ustvarili so enkratno morfologijo, ki še danes izraža takratna mestna estetska stremljenja.

Podobne primere lahko odkrijemo $\mathrm{v}$ angleških vaseh iz 18. stoletja, kjer so gradili "slikovite vasice" po podobah takratne "vaške idilike”, precej drugačne od "dolgočasnih" vasi 17 . stoletja, grajenih po klasičnih načelih oziroma vzorcih.
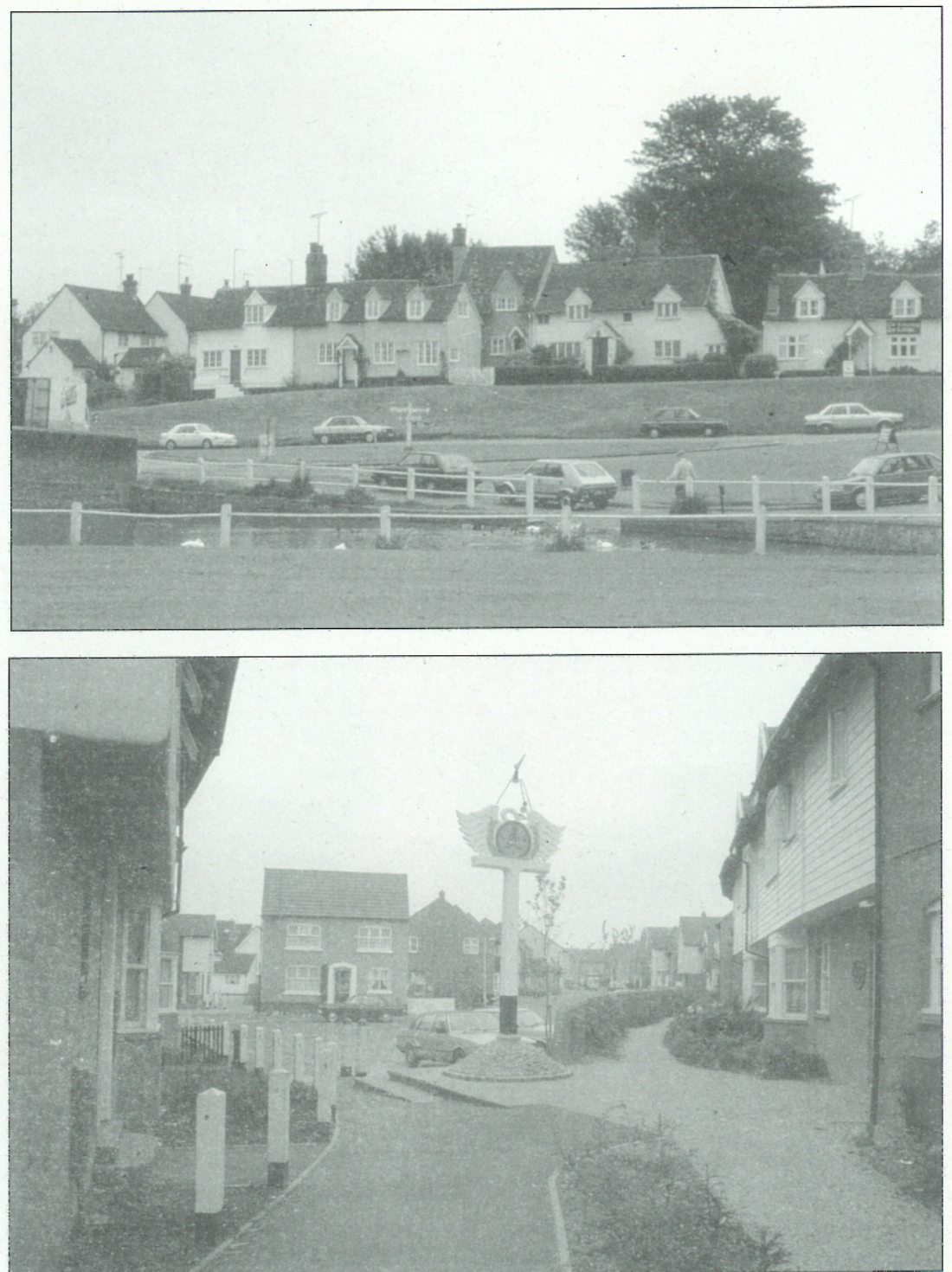

Slika 2 in 3: Vas Noake Bridge v grofiji Essex 


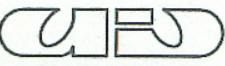

št. 32, 33/1997

Resnejše in precej bolj koordinirane napore $v$ opredeljevanju lokalnih in regionalnih značajev mest ter uporabi teh spoznanj $\mathrm{v}$ oblikovalski praksi lahko zasledimo $v$ zgodnjih letih modernizma, od leta 1890 naprej. Prve zamisli so preizkusili nemški geografi, ki so sistematično raziskovali in klasificirali nemška mesta. Pri tem so izpostavili njihove geomorfične (evolucijske) komponente in regionalne značilnosti. Schluter (1899) je na primer uvedel koncept "urbane krajine" (Stadtlandschaft) ter ga opredelil s pomočjo fizične oblike (zemljišča, parcele, zgradbe) in podobe mest. Postavil je tudi koncept "kulturne krajine" (Kul-
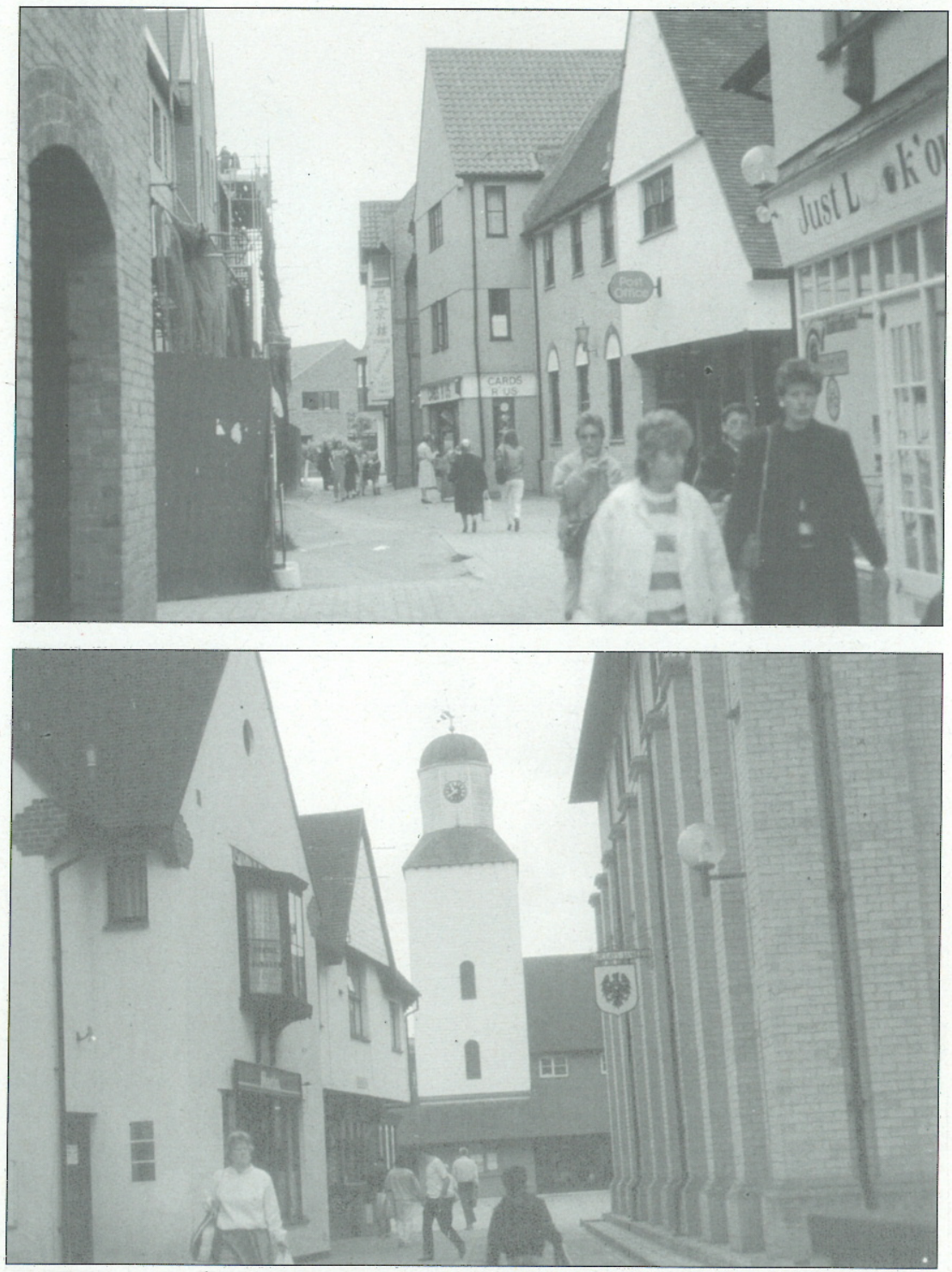

Slika 4 in 5: Vas South Woodham Ferres v grofiji Essex turlandschaft) ter opozoril na klasifikacijo naselbinskih tipov (morfologije), vzorce namenske rabe zemljišč in komunikacijskih sistemov kot osnovnih dejavnikov regionalnih značilnosti naselbin.

Njegovo delo so v 20. in 30 . letih tega stoletja nadaljevali Hassinger (1912), Geisler (1918) in Leighly (1929), pri čemer je Hassingerjeva arhitekturna klasifikacija stavb bistveno vplivala na raziskave o ohranjanju Dunaja.

Te zgodnje ideje o razlikovanju posebnosti morfoloških sestavin mest in ustreznem razumevanju mestnih značilnosti ter identitet, sta kot obsežen vir za oblikovalske zamisli uporabila tudi Otto Wagner in Camillo Sitte. Oba sta koncem 19. stoletja preizkusila svoje uvodne zamisli na Dunaju in jih pozneje razvila na drugih srednjein vzhodnoevropskih mestih.

Čeprav nekoliko različna v svojih oblikovalskih pristopih, sta oba ustvarjalca uporabila obstoječo morfološko strukturo Dunaja pri predlogih prihodnjega razvoja. $Z$ uvedbo radialno-koncentričnega cestnega sistema sta omejila obstoječe srednjeveško jedro in ponudila nov prostorski okvir mestne rasti. Pomembne javne in monumentalne stavbe sta vmeščala na ključne lokacije in tako poskrbela za pestrost ter zagotovila "berljivost" (urbanih struktur) uporabnikom.

Camillo Sitte je v knjigi Umetniško oblikovanje mest (1899) dobro povzel svoja razmišljanja, ki so še zlasti dragocena za današnje urbanistične oblikovalce. V knjigi Sitte poudarja ključno vlogo zgodovinskih urbanih krajin in morfoloških sestavin kot mogočnih ponudnikov čutnega doživljanja mest. Nadalje Sitte trdi, da lahko Z razumevanjem splošne podobe prostora (fiziognomije) razumemo prisotno preteklost in pripadajočo zgodovino. Če razumemo zgodovino, razumemo tudi identiteto mesta. Ali drugače, če izgubimo občutek za zgodovino, lahko izgubimo tudi lastno identiteto. 
V oblikovalskem pristopu je Sitte uporabljal raznovrstne tehnike bogatenja čutnega doživljanja mest. Kot enako pomembne je obravnaval kratke poglede npr. vijugastih srednjeveških cest, ki neprekinjeno ustvarjajo nove vizualne doživljaje ter jih pešec doživlja $v$ gibanju, in clolge poglede ob širokih avenijah, ki ustvarjajo povsem drugačen vizualen doživljaj ob hitrejših oblikah gibanja.

Ob koncu 19. stoletja so v mnogih evropskih mestih morali reševati težave povezovanja starih in rastočih novih mestnih prostorov. Mnogi evropski urbanisti so Wagnerjeve in Sittejeve zamisli v modificirani obliki tudi sprejeli. Mesti, kjer je vpliv teh zgodnjih oblikovalskih idej zaznaven, sta npr. Praga in Ljubljana.

V 20. in 30. letih tega stoletja je bilo v Severni Ameriki in Evropi narejenih veliko teoretskih študij o nadaljnjem opredeljevanju konceptualnega razumevanja lokalne in regionalne identitete. Nekatere študije so imele trdno oporo $\mathrm{v}$ razvoju konkretnih rešitev, npr. pri načrtovanju sistema podzemne železnice $\mathrm{v}$ Londonu. $\mathrm{V}$ tem projektu je bila uporabljena ideja o "celostni podobi" (corporate identity) s ciljem generiranja trdnega in komercialno uresničljivega $z$ načaja $z$ različnimi sestavinami sistema.

Nadaljnji teoretični in praktični predlogi ustvarjanja lokalne in regionalne identitete so $\mathrm{v}$ Veliki Britaniji bili predstavljeni v 50 . letih. Pobude so sovpadale $\mathrm{z}$ idlejo o ustvarjanju mestne krajine, kjer je poudarek na vizualno doživljajskih elementih urbanega okolja.

Z začetki v angleški šoli "slikovite krajine" in delih Cullena (1961) ta metoda predpostavlja, da vizualno doživljanje urbanega okolja in izboljšave na njem lahko dosežemo na objektiven način. Izboljšave je mogoče doseči $z$ enakovrednim razumevanjem fizičnih in vizualnih elementov, ki vplivajo na čutila. Fizični elementi arhi- tekturnega in urbanističnega oblikovanja so razumljeni kot deli umetnosti kompozicije.

Urbanističnooblikovalske teme, razvite iz tega pristopa, so se $\mathrm{v}$ Veliki Britaniji realizirale $s$ pomočjo urbanističnooblikovalskih priporočil in navodil (urban design guides, urban design briefs). Lokalne planerske službe so navodila uporabljale za pospeševanje oblikovanja novih naselij $v$ duhu krepitve lokalne in regionalne identitete grajenih okolij (Essex Design Brief, 1973).

Noake Bridge, Brentwood in South Woodham Ferres so značilni primeri naporov grofijskega sveta pri pospeševanju uporabe določenih regionalnih posebnosti v novih naseljih. Načela urbanističnega oblikovanja, ki sežejo od krajinskih dimenzij do elementov večjih ali manjših grajenih prostorov, kot so npr. tlorisi, gradiva, značilne skupine objektov, ornamentika in detajli, izvirajo iz sedanjih naselij $\mathrm{v}$ grofiji Essex. Upoštevanje priporočil-iz "navodil" je bilo pogoj za pridobitev dovoljenja za gradnjo. "Nova identiteta" Essexa je danes splošno sprejeta med prebivalci, ki v njej vidijo uspešno zamenjavo prejšnjih špekulativnih stanovanjskih zazidav (za trg) ali nakupovalnih središč $z$ oznako "kjerkoli".

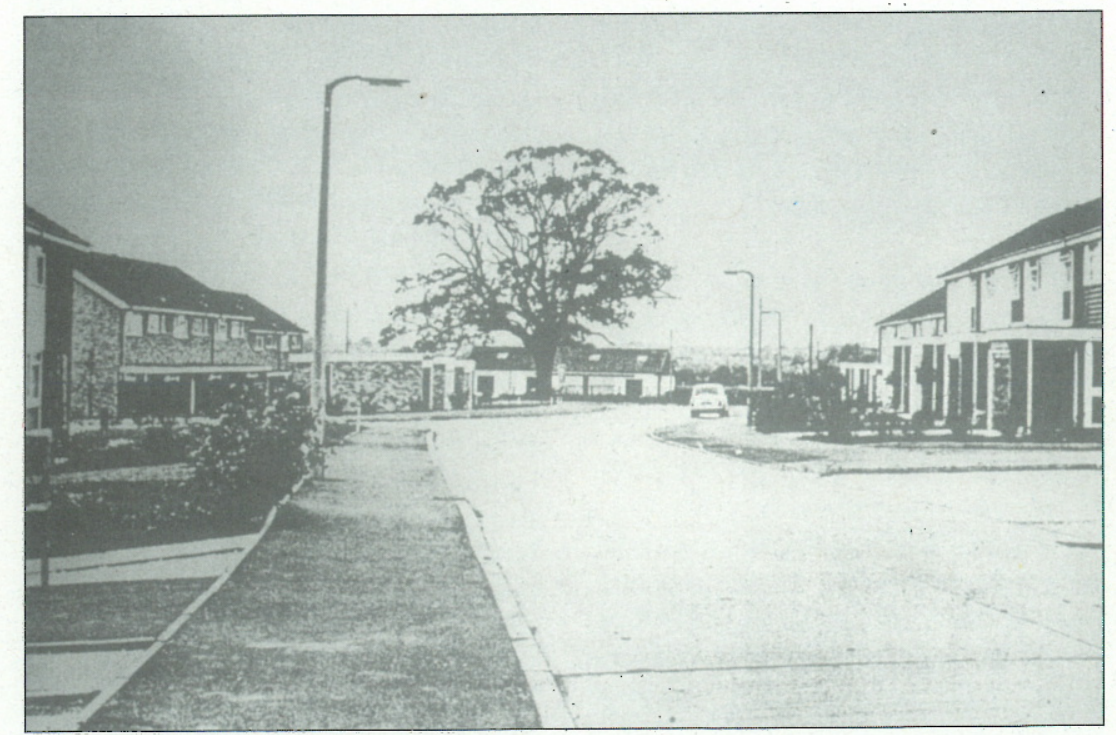

Slika 6: Tipična špekulativna zazidava za trg iz 60. let v grofiji Essex 
Podoben pomen imajo priporočila v urbanističnih navodilih za posamezne lokacije. Uspešni primeri iz britanske planerske prakse, izdelani za pospeševanje posameznih lokalnih značajev, so npr. Broadgate Arena (glej tudi Dimitrovska, 1992) in Richmond Riverside $\mathrm{v}$ Londonu. Na teh primerih je oblikovana kontekstualna povezava med obstoječo morfologijo in tipološkimi vzorci, s ciljem ustvarjanja novih prostorov, ki bi izražali neposredno lokalno identiteto. Broadgate Arena (arhitekt: Peter Foggo \& Arup Associates) "je odmev velikih georgianskih trgov, $\mathrm{v}$ tem primeru sosednjega Finsbury Circus" (Butina Watson, 1993, str. 67), Richmond Riverside (arhitekt Quinlan Terry) pa se $\mathrm{v}$ celoti vklaplja $\mathrm{v}$ splošno georgijansko morfološko tkivo okoliškega prostora.

V zadnjem času se pojavljajo poskusi integriranja priporočil in navodil $\mathrm{v}$ lokalne plane. Identifikacija t.i. območij oblikovanja (Hall, 1996) ali metod, ki jih predlaga Evans (1996), je pomemben doprinos $\mathrm{k}$ planiranju in oblikovanju lokalnih urbanih prostorov in manjših novih naselij. Evans predlaga definicije več urbanističnooblikovalskih kakovosti, ki so pomembne za doseganje lokalne raznovrstnosti in trajnosti naselij. Ob tem tudi predlaga orodja in metode za doseganje teh kakovosti. Specifična oblikovalska navodila, ki jih je Evans razvil in vgradil v občinski plan naselja Purbeck v grofiji Dorset (Purbeck District Plan, Dorset), bodo tako usmerjala bodoči razvoj sedanjih in novih naselij $v$ grofiji.

Podobne poskuse krepitve ali doseganja lokalne identitete izvajajo tudi v drugih razvitih in razvijajočih se državah. Centro Direzionale v Perugii (Aldo Rossi), stavbe v Maleziji (Jimmy Lim) ali strategija prenove glavne ceste $\mathrm{v}$ Bostonu so le nekateri boljši primeri sedanjih smeri razvoja, ki jih preizkušajo oblikovalci in drugi strokovnjaki ter uporabniki. Pomembno je razvijati konceptualne okvirje artikulacije lokalnih identitet $v$ posameznih kulturnih okoljih in orodja za možne prenose idej ali uporabljenih pristopov. $\mathrm{V}$ takem prenosu idej so še zlasti pomembna videnja lokalnih uporabnikov, ker predstavljajo ocenjevalsko skupino, ki lahko dešifrira sporočila načrtovalcev in drugih proizvajalcev grajenega okolja.

Dr. prof. Georgia Butina Watson, sopredstojnica, Joint Centre for Urban Design, Oxford Brookes University, Oxford, Velika Britanija

\section{Viri in literatura}

Abel, C.: Regional Transformations, Architectural Review, November, The Architectural Press, London 1986.

Bentley, I. et al.: Responsive Environments, The Architectural Press, London 1985.

Butina, G.: The Use of Urban History in the Design of Local Urban Areas, Urban Design Quarterly, No. 25, JCUD, Oxford, 1988.

Butina Watson, G.: The Art of Building Cities: Urban Structuring and Restructuring. V: Hayward, R. in McGlyn, S. eds: Making Better Places: Urban Design Now, Butterworth Heinemann Ltd., Oxford 1993

Conzen, M. R. G..: A study in town-plan analysis, Inst. Br. Geogr., Publ. No. 27, Alnwick, Northumberland 1960

Cullen, G. The Concise Totwnscape, The Architectural Press, London 1961. Dimitrovska, Andrews, Kaliopa: The Aesthetic Control of Development, Urbani izziv, št. 19, Urbanistični inštitut RS, Ljubljana 1992, str. 32-39.

Essex Design Guide for Residential Areas, Essex C. C., 1973.

Evans, D.: Urban Design Qualities in the Planning and Development of Small New Settlements, (neobjavljena doktorska disertacija), JCUD, Oxford Brookes University, Oxford 1966.

Geisler, W.: Die Deutsche Stadt: ein Beitrag zur Morphologie der Kuiturlandschaft, Stuttgart 1924.

Hall, A.: Design Control: Towards a New Approach, Butterworth Architecture, Oxford 1996.

Hassinger, H.: Kunsthistorischer Plan des 1. Bezirkes der Stadt Wien, Vienna 1912 .
HRH The Prince of Wales: A Vision of Britain, Doubleday, London 1989.

Jacobs, J.: The Death and Life of Great American Cities, Penguin, 196. Krier, R. : Urban Space, Academy Editions, London 1979.

Leighly, J. B.: The Towns of Malarden in Sweden: a study in urban morphology, University of California Publs., Geogr. 3., 1929

Lynch, K.:. The Image of the City, MIT, Cambridge Mass. 1968.

Nicolin, P.: Urban Identity and Technical Infrastructures, Lotus International, 1989.

Norberg-Schulz, C.: Genius Loci, Academy Editions, London 1980.

Ravetz, A.: The Government of Space, Faber and Faber, London 1986.

Relph, E.: The Modern Urban Landscape, Croom Helm, London 1987.

Rossi, A.: The Architecture of the City, MIT, Cambridge, Mass. 1982.

Rowe, P.: Civic Realism, MIT, Cambridge 1977

Samuels, I.: Urban Morphology in Urban Design, JCUD Research Note 19, Oxford 1985.

Sitte, C.: City Planning According to Artistic Principles, Random House, New York 1965.

Schluter, O.: Uber den Grundriss der Stadte, Z. Ges. Erdk. Berl. 34, 1899.

Vasak, L.: Achieving Reinforcement of City Image (neobjavljena magisterska naloga), JCUD, Oxford 1989.

Whitehand, J.: Background to the Urban Morphogenetic Tradition, IBG, London 1981. 